\title{
Insuficiência renal aguda
}

\section{Acute renal failure}

Tiago F. Nunes ${ }^{1,3}$, Denise M. Brunetta ${ }^{1,3}$, Christiane M. Leal ${ }^{2}$, Paula C. B. Pisi' ${ }^{1}$, Jarbas S. Roriz-Filho ${ }^{2,4}$

\begin{abstract}
RESUMO
A Insuficiência Renal Aguda (IRA) pode estar associada a várias etiologias no organismo humano, sendo este um dos motivos da importância dispensada àa esta doença. A prevenção é a principal ferramenta do médico e quando esta não foi possível, o tratamento visa afastar as principais causas, com investigação das demais e medidas de suporte para manter a viabilidade renal, muitas das vezes com êxito. A taxa de mortalidade em pacientes com IRA não se alterou muito nos últimos 30 anos. Os óbitos podem ocorrer em consequência da doença de base e não da própria IRA, pois o rim é um dos poucos órgãos cuja função pode ser substituída em parte por longos períodos (ex. diálise).
\end{abstract}

Palavras-chave: Lesão Renal Aguda. Diálise. Creatinina. Clearance de Creatinina, Hiperkalemia. Hiperpotassemia. Necrose Tubular Aguda.

\section{Introdução}

No início do século XX, insuficiência renal aguda foi descrita em Willian Osler's Textbook for Medicine (1909) como "Bright's disease", mas o termo insuficiência renal aguda foi creditado a Homer W. Smith descrito no capítulo "Acute Renal Failure related to traumatic injuries" no livro The Kidney-Structure and Funcional in Health and Disease (1951). ${ }^{1}$ Atualmente o termo Lesão Renal Aguda tem sido proposto.

Insuficiência renal aguda (IRA) é definida como perda rápida da função renal, com azotemia (elevação de uréia e creatinina). ${ }^{1}$ Existem mais de 35 definições na literatura. ${ }^{2}$ Lesão Renal Aguda tem sido proposta em substituição a IRA por ser mais amplo. Abrange desde pequenas alterações na função renal até mudanças que necessitam de terapia de substituição renal (TSR). ${ }^{2}$
Na tentativa de normatização da definição e classificação da IRA a Acute Dialysis Quality Initiative (ADQI) desenvolveu o critério de RIFLE (Tabela 1). Os três estágios de gravidade são baseados nas alterações da creatinina sérica ou no volume urinário, sendo considerado o pior resultado; já os dois critérios de evolução são definidos pela duração da perda de função renal. ${ }^{3}$

A creatinina sérica é o marcador mais usado para avaliação da função renal, ela sofre influência de fatores como massa muscular, hipercatabolismo e drogas, portanto pode superestimar ou subestimar a taxa de filtração glomerular (TFG). Além disso, há de se saber que pequenos aumentos no valor da creatinina correspondem a grandes perdas de TFG. Ferramentas como a fórmula de Cockcroft-Gault são usadas para a estimativa do clearence de creatinina $(\mathrm{ClCr}){ }^{4}$
1 Médico Assistente da Área de Clínica Médica do Hospital Estadual de Ribeirão Preto.

2 Ex-Médico Assistente da Clínica Médica do Hospital Estadual de Ribeirão Preto.

3 Pós-graduando da Área de Clínica Médica da FMRP-USP.

4 Professor Doutor da Faculdade de Medicina da Universidade de Fortaleza (CE)
Correspondência: Tiago Ferolla Nunes Hospital Estadual de Ribeirão Preto Avenida Independência, 4750. 14026-160- Ribeirão Preto - SP Telefone: $16-3602-7100$ 


\section{Tabela 1}

Critérios de RIFLE para lesão renal aguda, TFG, taxa de filtração glomerular; Creat, creatinina sérica; Vol, volume urinário. Os critérios são preenchidos conforme mudança na creatinina sérica em relação ao valor basal. Modificado de Kellum JA ${ }^{1}$.

\begin{tabular}{lll} 
& TFG & Volume urinário \\
\hline Risco & Aumento da Creat 1,5x ou queda de 25\% na TFG & $\mathrm{Vol}<0,5 \mathrm{ml} / \mathrm{Kg} / \mathrm{h}$ por $6 \mathrm{~h}$ \\
Lesão & Aumento da Creat 2x ou queda $>50 \%$ na TFG & $\mathrm{Vol}<0,5 \mathrm{ml} / \mathrm{Kg} / \mathrm{h}$ por $12 \mathrm{~h}$ \\
Falha (Insuficiência) & $\begin{array}{l}\text { Aumento da Creat 3x ou queda }>75 \% \text { na TFG ou } \\
\text { Creat }>4 \text { com aumento agudo }>0,5 \mathrm{mg} / \mathrm{dl}\end{array}$ & $\mathrm{Vol}<0,3 \mathrm{ml} / \mathrm{Kg} / \mathrm{h}$ por $24 \mathrm{~h}$ ou anúria por $12 \mathrm{~h}$ \\
Perda (Loss) & IRA persistente: perda completa da & \\
& função renal $>4$ semanas & \\
Rim terminal (ESKD) & ESKD, rim em estado terminal & \\
\hline
\end{tabular}

No futuro espera se que o uso de biomarcadores possa ser útil no diagnóstico da disfunção renal mesmo antes do desenvolvimento de alterações clínicas e/ou laboratoriais. ${ }^{5}$ Um biomarcador promissor é a Cistaina $\mathrm{C}$ sérica, cuja dosagem não é afetada pela idade, peso corporal, inflamação ou infecção. ${ }^{4}$

\section{Epidemiologia}

A IRA é uma complicação em cerca de 5\% das hospitalizações e até $30 \%$ das internações em
Unidade de Terapia Intensiva (UTI). Necrose Tubular Aguda (NTA) é responsável por mais de 50\% da IRA em pacientes hospitalizados e mais de $76 \%$ dos casos nos pacientes em UTI, sendo sepse a condição mais comumente associada. , 6,7

A prevalência de IRA varia de acordo com os valores de creatinina utilizados no diagnóstico em cada estudo e tem importante impacto na mortalidade (Figura 1$){ }^{8}$

A incidência de IRA aumenta com a idade, sendo 3,5 vezes maior nos pacientes acima de 70 anos $^{4}$,

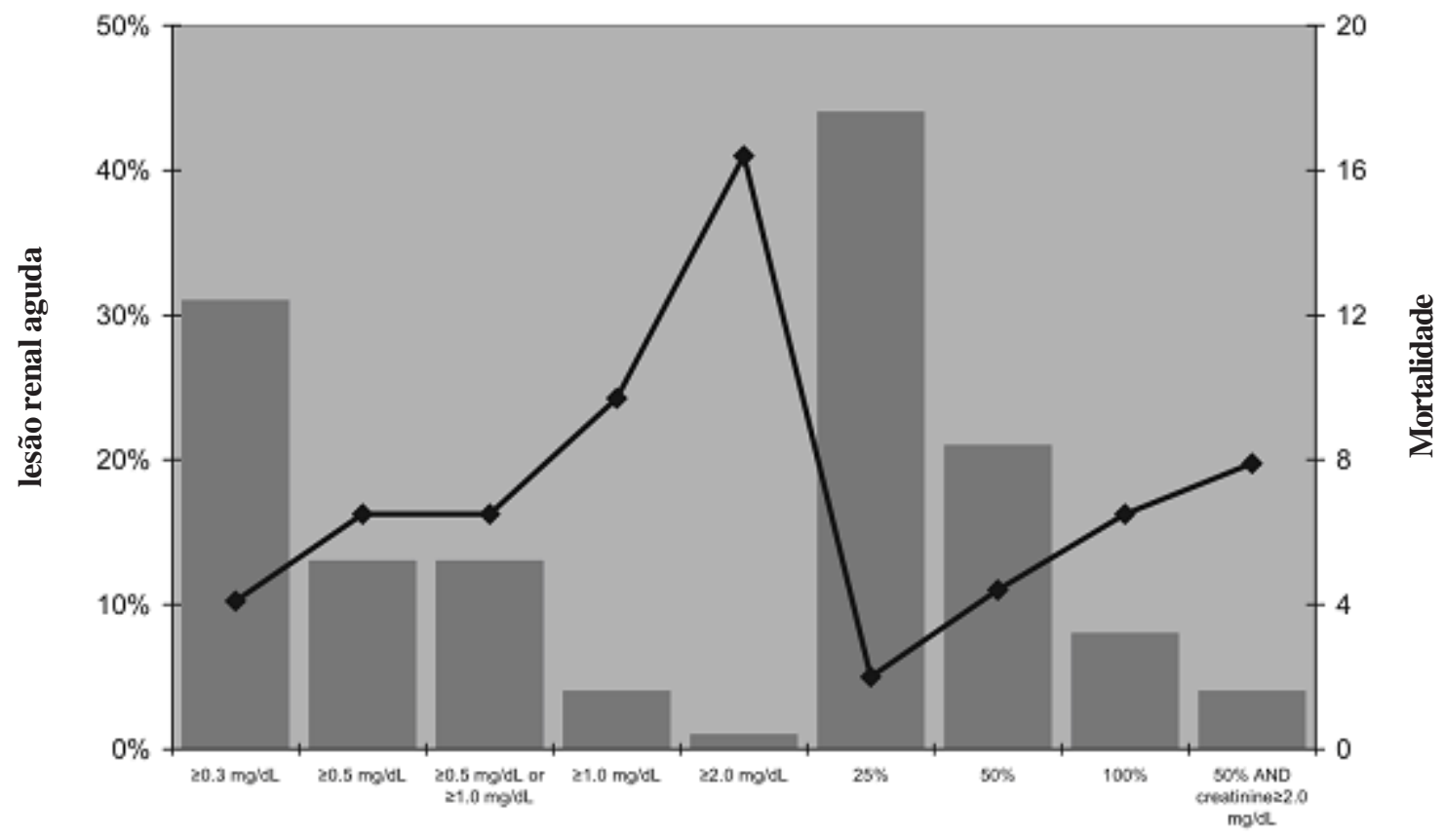

Figura 1: Diferentes definições de lesão renal aguda e efeito sobre a incidência e mortalidade $O$ mesmo grupo é classificado como IRA por nove diferentes definições, indicado no eixo horizontal: aumento absoluto da creatinina sérica de, respectivamente, $\geq 0,3 \mathrm{mg} / \mathrm{dl}$, $\geq 0,5 \mathrm{mg} / \mathrm{dl}$, $\geq 0,5 \mathrm{mg} / \mathrm{dl}$. (quando creatinina basal sérica de $<2 \mathrm{mg} / \mathrm{dl}$ ) ou $\geq 1,0 \mathrm{mg} / \mathrm{dl}$ (quando creatinina basal sérica de $\geq 2,0 \mathrm{mg} / \mathrm{dl} \mathrm{e} 5,0 \mathrm{mg} / \mathrm{dl}$ ), $1,0 \mathrm{mg} / \mathrm{dl}$, e $2,0 \mathrm{mg} / \mathrm{dl}$, ou aumento relativo da creatinina sérica de $25 \%, 50 \%, 100 \%$, ou $50 \%$ para um pico mínimo de $2,0 \mathrm{mg} / \mathrm{dl}$ OR, odds ratio. Modificado de Hoste EAJ. ${ }^{8}$ 
justificada pela perda progressiva da TFG com a ida$\mathrm{de},\left(1 \mathrm{ml} / \mathrm{min} / 1,73 \mathrm{~m}^{2}\right.$ por ano após os 30 anos $)$, associada à maior prevalência de comorbidades como Diabetes mellitus, Hipertensão arterial e hiperlipemia..,10 Pacientes que já possuem insuficiência renal crônica (IRC) tem chance maior de evoluir com rim terminal após episódio de agudização da insuficiência renal. ${ }^{11}$

IRA tem importantes implicações em saúde pública. Estágios avançados de RIFLE correspondem a maior tempo de permanência hospitalar ${ }^{11,12,13}$, necessidade de TSR e maior mortalidade (Figura 2). ${ }^{8}$

\section{Etiologia}

A IRA pode fazer parte de diversas doenças. Para fins de diagnóstico e tratamento costuma ser dividida em três etiologias. ${ }^{14}$

- Pré-renal: doenças que provocam hipoperfusão renal, sem comprometer a integridade do parênquima, cerca de $55 \%$;

- Renal: doenças que afetam diretamente o parênquima renal, cerca de $40 \%$;

- Pós-renal: doenças associadas à obstrução do trato urinário, cerca de 5\%;

\section{Insuficiência Renal Aguda - Pré-renal}

IRA pré-renal é a etiologia (Quadro 1) mais comum e representa resposta fisiológica à hipoperfusão renal leve a moderada, não há defeito estrutural nos rins. A dilatação auto-reguladora das arteríolas aferentes é máxima quando a pressão arterial sistêmica media é de $80 \mathrm{mmHg}$, portanto quando esta se encontra abaixo desses níveis pode precipitar queda na taxa de filtração glomerular (TFG) ${ }^{15}$, graus menores de queda da pressão arterial sistêmica média podem acometer indivíduos idosos ou pessoas com algumas comorbidades. Outro fator que pode levar a esta situação é o uso de fármacos como: AINEs e IECA. O diagnóstico é de suma importância, pois há reversibilidade do caso em um a dois dias, mas se persistir pode levar à NTA. Na tentativa de conservação hidrossalina a angiotensina II aumenta a reabsorção de água e sódio pelo néfron proximal, a aldosterona aumenta a reabsorção de água e sódio no néfron distal e a vassopressina aumenta a reabsorção de água no néfron distal, tudo isso levando a oligúria, urina concentrada, com mínima quantidade de sódio. ${ }^{14}$

Síndrome Hepatorrenal é uma forma particular e agressiva de IRA que acomete pacientes com

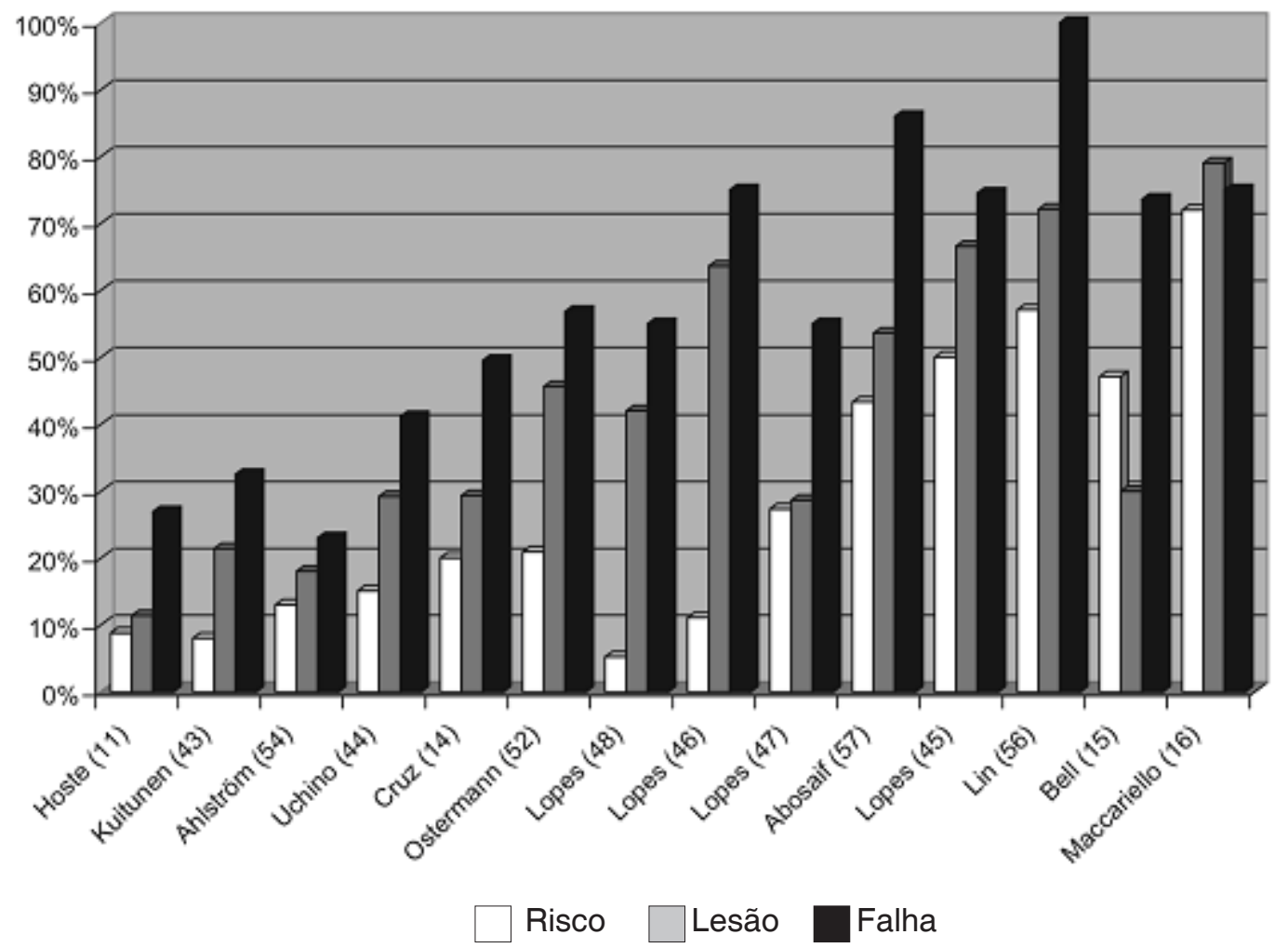

Figura 2: Mortalidade conforme estágio no critério de RIFLE em diferentes estudos. Modificado de Hoste EAJ². 
cirrose hepática ou outras hepatopatias, ocorre vasoconstricção intra-renal e retenção acentuada de sódio. Pacientes com hepatopatia avançada apresentam aumento no volume plasmático, mas redução no volume circulante efetivo em consequência da vasodilatação sistêmica e retenção portal de líquido. No paciente cirrótico é um sinal de mau prognóstico, sendo necessário recuperação da função hepática para melhora. ${ }^{14}$

\section{Insuficiência Renal Aguda - Renal}

IRA renal (Quadro 1) pode complicar diversas doenças que afetam o parênquima renal. A maioria dos casos (90\%) é desencadeada por isquemia ou nefrotoxinas que induzem NTA. Apenas 20 a 30\% da IRA renal não apresentam evidências clínicas ou morfológicas de NTA. Pode cursar com oligúria (NTA isquêmica, rabdomiólise, glomerulonefrites), anúria (necrose cortical aguda, algumas glomerulonefrites) e não oligúrica (NTA por aminoglicosídeos, fase de recuperação de NTA). ${ }^{14}$

Na NTA por hipoperfusão, há lesão isquêmica das células intraparenquimatosas renais, principalmente do epitélio tubular, podendo ocorrer recuperação em uma a duas semanas após recuperação da perfusão renal. Caso não ocorra recuperação da perfusão renal pode haver evolução para necrose cortical renal bilateral e insuficiência renal irreversível. ${ }^{14}$

A IRA isquêmica possui três fases: início, período inicial de hipoperfusão renal com duração de horas a dias; manutenção, tipicamente de uma a duas semanas onde ocorre lesão das células renais com débito urinário e TFG mínimos e a recuperação quan-

\section{Quadro 1: Causas de IRA ${ }^{14}$}

\section{IRA pré-renal:}

1- Hipovolemia: hemorragias, perdas gastrointestinais, perdas para terceiro espaço, queimaduras, excesso de diuréticos, febre, desidratação.

2- Diminuição do débito cardíaco: insuficiência cardíaca (IC), infarto agudo do miocárdio (IAM), tamponamento cardíaco, arritmias, ventilação mecânica com pressão positiva.

3- Alteração da relação entre resistência vascular sistêmica e renal: choque distributivo, uso abusivo de anti-hipertensivos, sepse, anafilaxia, noradrenalina, anfotericina B, ciclosporina, síndrome hepatorrenal.

4- Drogas: anti-inflamatórios não-esteroidais (AINEs), inibidores da enzima conversora de angiotensina (IECA), ciclosporina, contraste iodado.

5- Hiperviscosidade: mieloma múltiplo, macroglobulinemia, policitemia.

\section{IRA pós-renal:}

1- Obstrução ureteral bilateral: neoplasia de próstata, neoplasia de colo uterino, fibrose retroperitoneal idiopática, iatrogenia, obstrução intraluminal (cristais, edema, coágulos).

2- Obstrução na bexiga: neoplasia de bexiga, infecção, neuropatia.

3- Obstrução uretral: válvula congenital, hipertrofia prostática benigna (HPB), funcional.

\section{IRA renal:}

1- Obstrução vascular renal (bilateral ou unilateral com rim único funcionante): obstrução de veia renal ( trombose, compressão), obstrução de artéria renal ( aterosclerose, trombose, embolia, vasculite).

2- Doenças do glomérulo ou da microvasculatura renal: glomerulonefrite, vasculite, síndrome hemolítica urêmica, púrpura trombocitopênica trombótica, coagulação intravascular disseminada, esclerodermia, lupus eritematoso sistêmico.

3- Necrose tubular aguda: isquemia (igual a IRA pré-renal), toxinas (meios de contraste, antibióticos, ciclosporina, quimioterápicos, acetaminofen, rabdomiólise, hemólise, ácido úrico, oxalato, discrasia de leucócitos).

4- Nefrite intersticial: alérgica (antibióticos como betalactâmicos, sulfonamidas, trimetropim, rifampicina, AINEs, diuréticos, captopril), infecções (bacterianas, virais ou fúngicas), infiltração (linfoma, leucemia, sarcoidose) e idiopática.

5- Depósito e obstrução intratubular: proteínas do mieloma, ácido úrico, oxalato, aciclovir, metotrexato, sulfonamidas.

6- Rejeição de aloenxerto renal. 
do ocorre o reparo e regeneração das células parenquimatosas renais, pode ocorrer acentuado período poliúrico. ${ }^{14}$

A IRA renal por nefrotoxinas é aumentada nos idosos e nos pacientes com doença renal pré-existente4. Geralmente é reversível, previsível e passível de correção se identificada precocemente. As nefrotoxinas endógenas mais comuns são o cálcio, a mioglobina, a hemoglobina, o urato, o oxalato e as cadeias leves do mieloma. A vasoconstricção renal é o evento fundamental na IRA provocada por meios de contraste radiológico e ciclosporina. ${ }^{14}$ Ver drogas associadas à IRA na Tabela 2.

As características patológicas clássicas da IRA renal consistem em necrose focal do epitélio tubular com descolamento de sua membrana basal e oclusão da luz tubular por cilindros constituídos de células epiteliais íntegras ou em degeneração, restos celulares ou mucoproteínas. ${ }^{14}$

\section{Prevenção de lesão mediada por contrastes radiológicos iodados}

A administração de contrastes para exames radiológicos constituem importante causa reversível e prevenível de IRA, esta pode iniciar logo após a admi- nistração do contraste (Quadro 2). Existem contrastes iônicos, não iônicos de baixa osmolaridade e nãoiônicos com isoosmolaridade. ${ }^{16,17}$

Não há tratamento específico quando a IRA já está instalada e o manejo deve ser feito como em outras causas de necrose tubular aguda (NTA), visando manter o equilíbrio hidroeletrolítico e a volemia. $\mathrm{O}$ melhor tratamento é a prevenção. Manifesta se por elevação aguda (início 24 a 48 horas), porém reversível (máximo de três a cinco dias com reversão no decorrer de uma semana) dos níveis sanguíneos de uréia e creatinina. ${ }^{17}$

O tipo de contraste iodado é um fator importante na possibilidade de desenvolvimento de IRA, o principal benefício do uso dos contrastes não-iônicos é nos pacientes de alto risco (p. ex. creatinina sérica $\geq 1,5 \mathrm{mg} / \mathrm{dl}$ ou taxa de filtração glomerular $<60 \mathrm{ml} / \mathrm{min} /$ $1,73 \mathrm{~m}^{2}$ ), particularmente se diabéticos. ${ }^{16}$

Hidratação é a principal ferramenta de prevenção, porém ainda não está bem estabelecida qual é a melhor solução, se salina isotônica ou bicarbonato de sódio. Salina isotônica mostrou-se melhor que salina $0,45 \%$, e o principal benefício foi visto em diabéticos e naqueles que receberam mais de $250 \mathrm{ml}$ de contraste. Uso de bicarbonato de sódio tem sido estudado desde

\section{Tabela 2}

Drogas associadas à IRA. Modificado de Thadani $\mathrm{R}^{21}$.

\section{Mecanismo \\ Redução da perfusão renal com alteração da hemodinâmica intrarrenal}

Toxicidade tubular direta

Toxicidade tubular induzida por heme pigmento (rabdomióise)

Obstrução intratubular por precipitação de agentes ou metabólitos

Nefrite intersticial alérgica

Síndrome hemolítica urêmica

\section{Droga}

AINEs, IECA, ciclosporina, tacrolimus, agentes de radiocontraste, afotericina $\mathrm{B}$

Aminoglicosídeos, agentes de radiocontraste, cisplatina, ciclosporina, tacrolimus, anfotericina B, metotrexate, foscarnet, pentamidina, solventes orgânicos, metais pesados, imunoglobulina intravenosa

Cocaina, etanol, lovastatina

Aciclovir, sulfonamidas, etilenoglicol, metotrexate

Penicilinas, cefalosporinas, sulfonamidas, rifampicina, ciprofloxacina, AINEs, diuréticos tiazídicos, furosemida, cimetidina, alopurinol

Ciclosporina, tacrolimus, quinidina, estrogênios conjugados 
a demonstração que a alcalinização da urina pode proteger contra os radicais livres. O uso de $3 \mathrm{ml} / \mathrm{kg} /$ hora uma hora antes do uso do contraste seguido de $1 \mathrm{ml} / \mathrm{kg}$ nas próximas seis horas mostrou-se benéfico na prevenção da IRA. A hidratação oral não deve ser usada isoladamente. ${ }^{17,18,19}$

Acetilcisteína é considerada com propriedades antioxidantes e vasodilatadoras. Considerando ser bem tolerada, baixo custo pode ser usada em pacientes de alto risco, sempre acompanhada de outras medidas preventivas. A dose a ser usada é questionável atualmente, recomenda se uso de $600-1200 \mathrm{mg}$ via oral duas vezes ao dia no dia anterior e no dia do exame, o uso intravenoso não costuma ser recomendado. ${ }^{17}$

\section{Uso de contraste de RNM}

A maioria dos contrastes usados em RNM é de gadolínio, cuja principal excreção é renal. Nos pacientes com insuficiência renal moderada a grave existe $o$ risco de fibrose sistêmica nefrogênica além do risco de nefrotoxicidade semelhante ao ocorrido com os contrastes iodados. Estes fatos ocorrem principalmente quando os pacientes possuem $\mathrm{TFG}<30 \mathrm{ml} / \mathrm{min} .{ }^{14}$

\section{Insuficiência Renal Aguda - Pós-renal}

Tem a menor prevalência dentre os três tipos (Figura 3) de IRA e exige a ocorrência de obstrução com repercussão renal bilateral, ou unilateral com rim único, como ocorre na obstrução uretral, do colo vesical, ureteral bilateral ou unilateral em rim único. A obstru- ção do colo vesical é a causa mais comum e em geral é decorrente de doença prostática, bexiga neurogênica ou tratamento com anticolinérgicos. A obstrução aguda inicialmente produz vasodilatação arteriolar com aumento da TFG, em seguida, são produzidas substâncias vasoconstrictoras reduzindo a TFG. Se a obstrução permanecer por mais de duas a quatro semanas pode ocorrer fibrose intersticial, atrofia tubular progressiva e nefropatia obstrutiva crônica. ${ }^{14} \mathrm{O}$ diagnóstico da obstrução é usualmente feito pela ultrassonografia, com sensibilidade e especificidade de $98 \%$ e $78 \%$ respectivamente. ${ }^{20}$

\section{Manifestações clínicas}

Inicialmente é importante estabelecer se a insuficiência renal estabelecida é um processo agudo ou crônico, isso é fácil de estabelecer caso os exames de laboratório demonstrem elevação recente de uréia e creatinina. Achados de insufuciência renal crônica (IRC) inclui, neuropatia, anemia, rins diminuídos de tamanho ao exame ultrassonográfico. Lembrando que podemos ter IRC com rins de tamanho normal na nefropatia diabética, amiloidose e doença renal policística. ${ }^{14}$

IRA pré-renal se manifesta com sede, hipotensão ortostática, redução de pressão venosa jugular, sinais de desidratação. Considere sempre buscar a causa base, como insuficiência cardíaca avançada, sepse, hepatopatia crônica com hipertensão portal ou causas de diminuição do volume sanguíneo efetivo, lembrando de avaliar também uso de IECA e AINEs. ${ }^{14,21}$

\section{Quadro 2}

Sumário de recomendações na prevenção da nefropata por contraste ${ }^{17}$.

- uso, quando possível, de exame de ultrassonografia, ressonância nuclear magnética (RNM) sem gadolinio ou tomografia computadorizada (CT), sem o uso de contraste;

- uso de baixas doses de contraste, evitar exames contrastados de repetição em espaço de tempo curto, usar pequena quantidade de contraste;

- evitar contrastes de alta osmolaridade;

- se possível, usar contrastes isoosmois;

- evitar depleção de volume e uso de anti-inflamatórios não-hormonais (AINE);

- se não há contraindicações, realizar expansão volêmica. Solução salina isotônica antes e após a realização do exame;

- uso de bicarbonato de sódio $3 \mathrm{ml} / \mathrm{kg}$ uma hora antes do exame e $1 \mathrm{ml} / \mathrm{kg}$ nas próximas seis horas após o procedimento. A solução pode ser preparada com $150 \mathrm{mEq}$ de bicarbonato de sódio $(1 \mathrm{mEq} / \mathrm{ml}$ de bicarbonato de sódio) adicionada a $850 \mathrm{ml}$ de solução glicosada ou água;

- uso de acetilcisteína;

- uso de contraste não-iônico de baixa osmolaridade ou isosmol. 


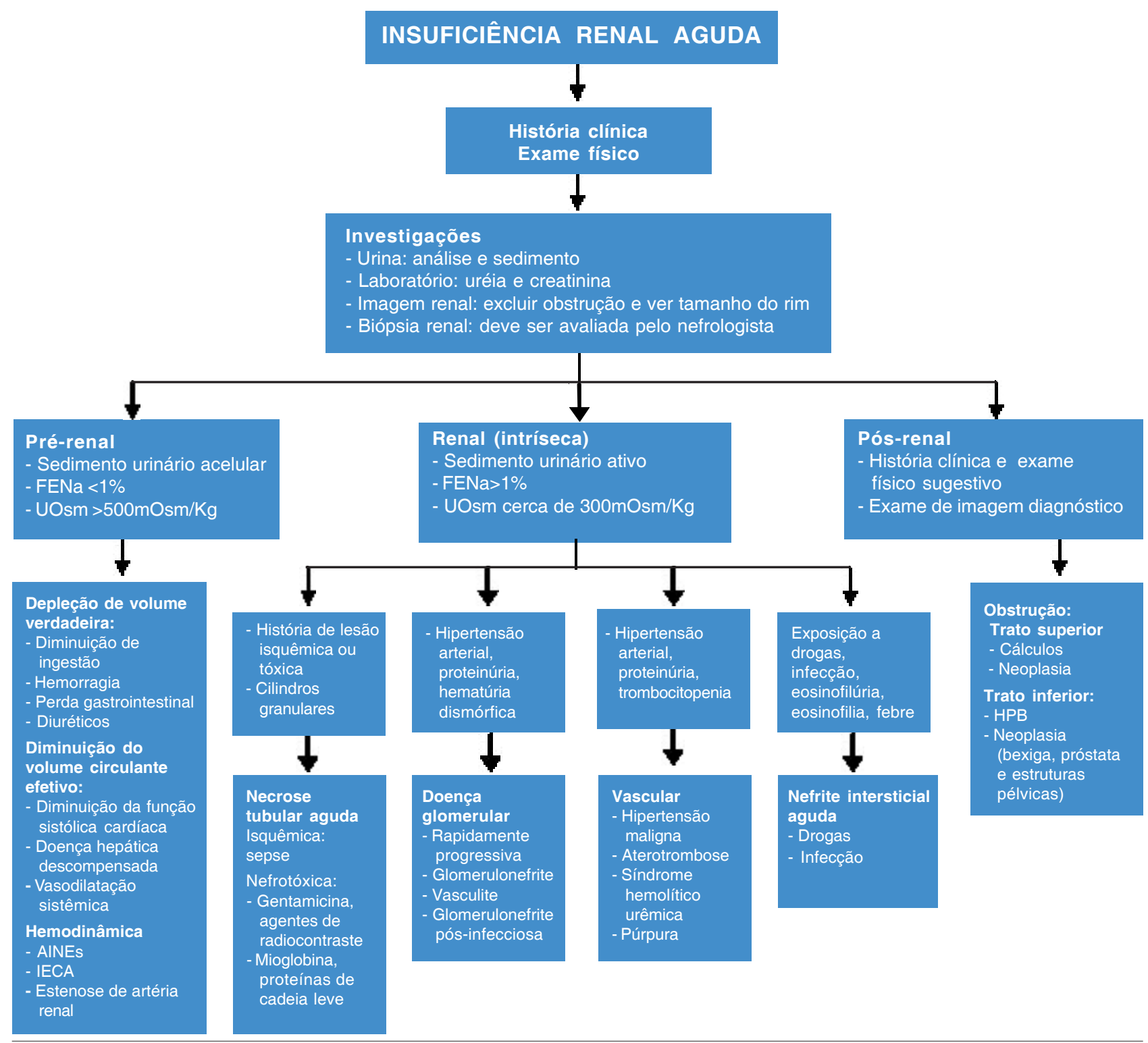

Figura 3: Manejo da IRA.Modificado de Cheung $\mathrm{CH}^{4}$.

A IRA renal, quando isquêmica costuma se manifestar como complicação de hipoperfusão grave, já a nefrotóxica exige extensa revisão das medicações em uso e dos procedimentos realizados pelo paciente. Apesar da IRA renal nefrotóxica e isquêmica corresponderem à maioria dos casos, devemos pela história e exame físico buscar informações que poderiam levar ao diagnóstico de outras causas. Dentre estas informações podemos encontrar: dor no flanco associado há fibrilação atrial ou IAM recente pensar em oclusão de veia ou artéria renal; presença de nódulos subcutâneos, placas retinianas, livedo reticularis, isquemia digital, manipulação recente da aorta pode ser indício de ateroembolização; sedimento urinário ativo, edema, hipertensão e oligúria considerar hipótese de glomerulonefrite; hipertensão grave com cefaléia, retinopatia, papiledema sugerem hipertensão maligna; ingestão recente de drogas, febre, exantema ou artragias sugerem nefrite intersticial aguda. ${ }^{14,21}$

A IRA pós-renal costuma apresentar-se com dor suprapúbica ou em flanco associada à bexiga palpável, dor no flanco em cólica que se irradia para a bexiga pode sugerir obstrução ureteral; nictúria, polaciúria e hesitação costumam ocorrer na síndrome prostática. O diagnóstico propriamente dito ocorre com a rápida melhora da função renal após a desobstrução e realização de exames radiológicos que comprovem essa obstrução. ${ }^{14,21}$ 


\section{Diagnóstico diferencial}

A análise bioquímica do plasma e urina pode contribuir para o diagnóstico diferencial entre as duas principais causas de insuficiência renal ${ }^{14}$ (Tabela 3 ).

\section{Exame de urina}

Anúria costuma acompanhar a IRA pós-renal, mas também pode ocorrer nos casos graves de IRA renal ou pré-renal. ${ }^{14} \mathrm{~A}$ IRA pode ser oligúrica (diurese inferior a $400 \mathrm{ml} / 24 \mathrm{~h}$ ), não oligúrica ou anúrica (menos de $100 \mathrm{ml} / 24 \mathrm{~h}){ }^{22}$

A análise da urina é considerada o teste nãoinvasivo mais importante na investigação etiológica da IRA. ${ }^{22} \mathrm{O}$ sedimento urinário costuma ser sem células na IRA pré-renal, com formação de cilindros hialinos. Na IRA pós-renal o sedimento também costuma ser inativo, apesar de poder ocorrer hematúria e/ou piúria nos casos de obstrução intraluminal ou doença prostática. Proteinúria $(<1 \mathrm{~g} / \mathrm{dia})$, geralmente cilindros hemáticos indicam lesão glomerular, cilindros leucocitários e granulosos não pigmentados sugerem nefrite intersticial e cilindros largos indicam doença renal crônica. Proteinúria $>1$ g/dia sugere lesão da barreira de ultrafiltração glomerular ou excreção de proteínas de cadeia leve do mieloma. ${ }^{14}$

A presença de hemácias dismórficas no sedimento urinário, principalmente na forma de acantócitos pode sugerir hematúria de origem glomerular. Os ci- lindros encontrados na urina têm na sua composição a proteína de Tamm-Horsfall. A classificação dos cilindros é feita conforme sua composição e aparência à microscopia óptica sendo:

- hialinos: compostos apenas por proteínas de TammHorsfall, ocorrem em desidratação, exercícios físicos intensos, ou associados à proteinúria glomerular;

- hemáticos: compostos de glóbulos vermelhos, mostrando origem glomerular, como nas glomerulonefrites e vasculites;

- algodonosos: compostos de leucócitos, como nas inflamações parenquimatosas;

- granulares: compostos por células epiteliais tubulares, restos celulares associados à debris, característicos de pacientes com NTA;

- lipóides: ocorrem em casos de proteinúria maciça, como nas síndromes nefróticas. ${ }^{22}$

\section{Índices de insuficiência renal}

O sódio $(\mathrm{Na})$ sofre intensa reabsorção do filtrado glomerular na IRA pré-renal, no intuito de restaurar o volume intravascular, já na IRA intrínseca (renal) isso não ocorre devido à lesão das células tubulares. A creatinina não é reabsorvida em nenhuma das duas situações. Portanto, o paciente com IRA prérenal possui fração de excreção de sódio $(\mathrm{FENa})<1 \%$ exceto quando estes pacientes estão em uso de diuré-

\section{Tabela 3}

Diagnóstico diferencial na IRA renal x IRA pré-renal pelos índices urinários.

\begin{tabular}{|c|c|c|}
\hline Índice diagnóstico & IRA pré-renal & IRA renal intrínse \\
\hline \multicolumn{3}{|l|}{ Fração de excreção de $\mathrm{Na}$} \\
\hline UNa x PCr x 100 & $<1$ & $>1$ \\
\hline \multicolumn{3}{|l|}{$\mathrm{PNa} \times \mathrm{UCr}$} \\
\hline Concentração urinária de Na mmol/l & $<10$ & $>20$ \\
\hline Razão entre creatinina urinária e plasmática & $>40$ & $<20$ \\
\hline Densidade urinária & $>1020$ & Cerca de 1010 \\
\hline Osmolalidade urinária mosmol/ $\mathrm{Kg} \mathrm{H}_{2} \mathrm{O}$ & $>500$ & Cerca de 300 \\
\hline Razão uréia/ creatinina plasmática & $>40$ & $<20-30$ \\
\hline \multicolumn{3}{|l|}{ Índice de insuficiência renal } \\
\hline $\mathrm{UNa}$ & $<1$ & $>1$ \\
\hline
\end{tabular}

Sedimento urinário

Cilindros hialinos

Cilindros granulosos acastanhados

UCr - creatinina urinária, $\mathrm{PCr}$ - creatinina plasmática, UNa - sódio urinário, PNa - sódio plasmático, $\mathrm{Na}$ - sódio, índice mais sensível ${ }^{27}$ 
ticos. A FENa também costuma ser $<1 \%$ na IRA causada por obstrução do trato urinário, glomerulonefrite e doenças vasculares. ${ }^{14,23}$

\section{Biópsia renal}

É considerada nos casos onde a IRA pré-renal e pós-renal foram excluídas mas a avaliação clínica e laboratorial sugere diagnósticos que não lesão isquêmica ou nefrotóxica, como por exemplo, glomerulonefrite, vasculite, síndrome hemolítico urêmica, púrpura trombocitopênica trombótica e nefrite intersticial alérgica. ${ }^{14}$

\section{Exames radiológicos}

São muito úteis na exclusão, principalmente na IRA pós-renal, a dilatação pelvicalicial tem sensibilidade de $98 \%$ na presença de obstrução do trato urinário, mas pode não estar presente imediatamente após a obstrução ou em pacientes com obstrução uretral. ${ }^{14}$

Radiografia simples de abdome e ultrassonografia (USG) de rins e vias urinárias devem ser realizados nos casos de IRA. A radiografia raramente é útil mas pode mostrar cálculos. USG é o exame de escolha para analisar inicialmente obstrução do trato urinário, lembrando que pode ocorrer um prazo variável de alguns dias até que se verifique dilatação pielocalicial na USG. A tomografia de rins e vias urinárias pode mostrar dados não visualizados na USG como alguns cálculos e obstruções, e ainda na fase contrastada, a tomografia pode mostrar pielonefrites agudas ou tromboses venosas. Angioressonância pode ser de grande auxílio no caso de lesões vasculares. ${ }^{22}$

\section{Prevenção}

Como não existe tratamento específico, a prevenção assume importante papel. A restauração do volume intravascular diminui significativamente a incidência de IRA após grandes cirurgias, traumatismos, queimaduras e diarréia.

A incidência de IRA por nefrotoxinas pode reduzir significantemente quando se individualiza as medicações, com o uso de doses dos antibióticos conforme a TFG, lembrando que o uso isolado da creatinina pode superestimar a TFG, portanto para fins posológicos aconselha se o uso de fórmula de CockcroftGault:
Diuréticos, AINEs, IECA, e outros vasodilatadores devem ser usados com cautela. ${ }^{14,24}$

\section{Tratamento}

O tratamento da IRA é multifatorial, visando aperfeiçoar a recuperação da função renal e prevenção de novas lesões, mesmo antes da definição da causa da IRA, inicia se com a correção da volemia, restabelecimento do equilíbrio eletrolítico e controle das manifestações de uremia. ${ }^{4}$

Sempre se tenta afastar IRA renal e pós-renal, pois simples medidas podem ter grande impacto sobre a evolução do paciente. Deve-se logo proceder a coleta de sangue e urina visando o diagnóstico etiológico, pois procedimentos seguintes como o uso de diuréticos podem comprometer essa avaliação. ${ }^{22}$

A nutrição é fundamental, os idosos são particularmente susceptíveis, pois estima se que $1 \%$ dos idosos da comunidade, $20 \%$ dos hospitalizados e $37 \%$ dos institucionalizados estão subnutridos. ${ }^{25}$ Pacientes com IRA são de alto risco nutricional, pois são frequentemente hipercatabólicos e com baixa ingestão de nutrientes. ${ }^{26}$ A ingestão de líquidos e eletrólitos deve ser monitorada e a orientação dietética deve controlar também algumas consequências da uremia. Nutrição enteral ou parenteral deve ser instituída assim que possível. A infusão de grandes quantidades de aminoácidos e glicose, na fase inicial da IRA, pode aumentar o consumo renal de oxigênio, agravando a lesão tubular e a disfunção renal. ${ }^{27}$

\section{Tratamento das complicações}

Evitar iatrogenia: todas as medicações em uso pelo paciente devem ser revisadas, a dosagem e frequência de administração devem ser corrigidas pela função renal caso seja necessário. Evitar uso de agentes nefrotóxicos como AINEs, meios de contraste radiológicos e aminoglicosídeos. ${ }^{4,14}$

Hipercalemia é uma emergência médica pelo risco aumentado de arritmias e quando as medidas clínicas não são suficientes o paciente pode ser encaminhado à hemodiálise (Quadro 3).

Otimizar fluidos e hemodinâmica: quando detectada a hipovolemia, o volume intravascular deve 


\section{Quadro 3}

Tratamento da hipercalemia ${ }^{30,31}$.

1. Confirmar a hipercalemia (coleta de sangue sem torniquete);

2. Interromper a administração de potássio;

3. Realizar eletrocardiograma (ECG);

4. Se tiver alteração eletrocardiográfica, realizar infusão endovenosa (EV) de cálcio: gluconato de cálcio 10\%, 10ml, EV, em dois a três minutos, pode ser repetido se permanecerem as alterações;

5. Glicose + Insulina: insulina regular 10UI em Glicose 50\%, $100 \mathrm{ml}$ em cinco a 10 minutos, EV. Início de ação com 30min, pico em 60min;

6. Beta 2 agonista: inalação de salbutamol;

7. Bicarbonato de sódio: se tiver acidose, deve calcular o déficit ( formula de Ash: Peso x BE x 0,3) e infundir metade do déficit, quando não existe acidose pode se usar doses menores. A infusão deve ser Bicarbonato de sódio 8,4\% EV em 15 a 20 minutos;

8. Diurético de alça: furosemida 40 a $80 \mathrm{mg}$ EV em bolus;

9. Resina de troca iônica: a mais usada em nosso meio é o poliestirenosulfato de cálcio (Sorcal ${ }^{\mathrm{TM}}$ ), elimina o potássio nas fezes. Posologia habitual de 15 a 30 gramas via oral a cada 6 a 8 horas, também pode ser feito via retal.

10. Diálise.

ser restituído com solução salina, não havendo indícios que o uso de colóides ou outros expansores sintéticos de plasma acrescentem qualquer benefício. Caso não seja possível atingir a pressão arterial média adequada mesmo com a volemia otimizada, deve considerar o uso de drogas vasoativas, sendo a noradrenalina preferencial em relação a dopamina. ${ }^{22,28}$

Oligúria: não há indícios que a conversão de IRA oligúrica para não oligúrica com uso de diuréticos (furosemida é o mais usado em nosso meio) modifique a evolução ou a mortalidade dos pacientes. Porém o manejo do paciente é melhor quando o mesmo tem bom volume urinário, além de diminuir as complicações advindas da hipervolemia. ${ }^{22}$

Acidose metabólica pode acarretar em vasodilatação sistêmica, aumentar o risco de arritmia e hipercalemia. ${ }^{4}$ Geralmente a acidose metabólica secundária a IRA não é grave, não é necessário o tratamento caso o bicarbonato sérico seja superior a $15 \mathrm{mEq} / \mathrm{L}$ ou o $\mathrm{pH}$ superior a 7,2. A quantidade de bi- carbonato a ser administrado, se necessário é calculada pela equação de déficit de bicarbonato:
Déficit de $\mathrm{HCO}_{3}(\mathrm{mEq} / \mathrm{L})=0,5 \times$ peso $(\mathrm{kg}) \times\left(24-\mathrm{HCO}_{3}\right.$ sérico atual $)$

\section{Diálise}

Deve ser indicada de urgência quando: hipervolemia sem resposta com terapia diurética; hipercalemia ou acidose metabólica refratária ao tratamento clínico; intoxicação por drogas ou toxinas dialisáveis quando indicado; uremia (encefalopatia, pericardite, diástase hemorrágica); e azotemia persistente sem causa específica. ${ }^{29} \mathrm{O}$ prognóstico dos pacientes com IRA necessitando de diálise continua sombrio, com taxas de mortalidade altas. O momento ideal para o início da diálise e o método dialítico de escolha depende de cada paciente ${ }^{29}$ e não pertence ao escopo desse artigo. 


\section{ABSTRACT}

The Acute Renal Failure (ARF) can be related to several etiologies in the human organism, being one of the reasons of the importance given to this disease. The prevention is the doctor's main tool and, when it is not possible, the treatment looks forward repelling the main causes, also investigating the others and keeping supportive care to maintain the renal viability, most of the times, successfully. The mortality rate in patients with ARF did not change much in the last 30 years. The deaths can occur as a result of the underlying disease and not of ARF, because the kidney is one of the few organs which function can be substituted, in part, for long periods (ex. dialysis).

Key words: Acute Kidney Injury. Dialysis. Creatinine. Creatinine Clearance. Hyperkalemia. Kidney Tubular Necrosis, Acute.

\section{Referências Bibliográficas}

1. Kellum JA. Acute Kidney Injury. Crit Care 2008;36:141-5.

2. Kellum JA, Levin N, Bouman C, Lameire N. Developing a consensus classification system for acute renal failure. Curr Opin Crit Care 2002;8:509-14.

3. Bellomo R, Ronco C, Kellum JA, Mehta RL, Palevsky P. Acute renal failure - definition, outcome measures, animal models, fluid therapy and information technology needs: the Second International Consensus Conference of the Acute Dialysis Quality Initiative (ADQI) Group. Crit Care 2004;8:R204-12.

4. Cheung M, Ponnusamy A, Anderton JG. Management of acute renal filure in the elderly patitent. Drugs Aging 2008; 25:45576.

5. Venkataraman R, Kellum JA. Defining acute renal failure: The RIFLE criteria. J Intensive Care Med 2007;22:187-93.

6. Bagshaw, SM, Langenberg C, Wan L, May CN, Bellomo R. A systematic review of urinary findings in experimental septic acute renal failure. Crit Care Med 2007;36:1592-8.

7. Bagshaw SM, Langenberg C, Bellomo R. Urinary biochemistry and microscopy inseptic acute renal failure: A systematic review. Am J Kidney Dis 2006;48:695-705.

8. Hoste EAJ, Shurgers M. Epidemiology of acute kidney injury: How big is this problem? Crit Care 2008;36:146-51.

9. Coresh J, Astor BC, Greene T, Eknoyan G, Levey AS. Prevalence of chronic kidney disease and decreased kidney function in the adult US population: Third National Health and Nutrition Examination Survey. Am J Kidney Dis 2003;41:112.

10. Bleyer AJ, Shemanski LR, Burke GL, Hansen KJ, Appel RG. Tobacco, hypertension, and vascular disease: risk factors for renal functional decline in an older population. Kidney Int 2000;57: 2072-9.

11. Hoste EA, Clermont G, Kersten A, Venkataraman R, Angus DC, De Bacquer D, Kellum JA. RIFLE criteria for acute kidney injury are associated with hospital mortality in critically ill patients: A cohort analysis. Crit Care 2006;10:R73.

12. Prescott GJ, Metcalfe W, Baharani J, Khan IH, Simpson K, Smith WC, MacLeod AM. A prospective national study of acute renal failure treated with RRT: Incidence, aetiology and outcomes. Nephrol Dial Transplant 2007;22:2513-9.

13. Bagshaw SM, George C, Bellomo R. Changes in the incidence and outcome for early acute kidney injury in a cohort of Australian intensive care units. Crit Care 2007;11:R68.
14. Hugh RB, Barry $M$, Brenner BM, Insuficiência renal aguda em Harrison Medicina Interna. 15ำ ed. São Paulo: McGrawHill, 2002

15. Abuelo JG. Normotensive Ischemic Acute Renal Failure. N Engl J Med 2007;357:797-805.

16. Parfrey PS, Griffiths SM, Barret BJ. Contrast material inducetrenal failure in pacients with diabetes mellitus, renal insufficiency, or both. N Engl J Med 1989;320:143-8.

17. Barret BJ, Parfrey PS. Prevent Nephopathy induced by contrast medium. N Engl J Med 2006;354:379-86.

18. Solomon R. Contrast imedium induced acute renal failure. Kidney Int 1998;53:230-242.

19. Murphy SW, Barret BJ, Parfrey PS. Contrast Nephropaty. J Am Soc Nephrol 2000;11:177-82.

20. Cronan JJ. Contemporany concepts in imaging urinary tract obstruction. Radiol Clin North Am 1991;29:527-42.

21. Thadhani R, Pascual M, Bonventre JV. Acute Renal Failure. N Engl J Med 1996;334(22):1448-57.

22. Martins HS, Scalabrini Neto A, Velasco IT. Emergências clínicas baseadas em evidências. Rio de Janeiro: Atheneu, 2006.

23. Costa JA, Vieira Neto OM, Moyses Neto M. Insuficiência renal aguda. Medicina Ribeirão Preto 2003;36:307-24.

24. Venkataraman R. Can we prevent acute kidney injury? Crit Care Med 2008;36:S166-71.

25. Guigoz Y, Lauque S, Vellas BJ. Identifying the elderly at risk for malnutrition: the Mini Nutritional Assessment. Clin Geriatr Med 2002;18:737-57.

26. Wolfson M, Kopple JD. Nutritional management of acute renal failure. In LAZARUS, JM E BRENNER BM. Acute Renal Failure, $3^{a}$ ed. Churchill, New York, 1993. p 467-85

27. Mith WE, Wilmore DW. Nutritional consideration in the treatment of acute renal failure. In LAZARUS JM E BRENNER BM. Acute Renal Failure, $2^{a}$ ed Churchill, New York, p 743-65, 1988.

28. Martin C, Papazian L, Perrin G, Saux P, Gouin F. Norepinephrine or dopamine for treatment of hiperdinamic shock? Chest 1993;103:1826-31.

29. Palevsky PM. Indication and timing of renal replacement therapy in acute kidney injury. Crit Care Med 2008;36(4):224-8.

30. Vieira Neto OM, Moysés Neto M. Distúrbios do Equilíbrio Hidroeletrolítico. Medicina Ribeirão Preto 2003;36:325-7.

31. Mieko E, Nagibe A. Medicina de Urgência. São Paulo. Ed. Manole, 2004 